\title{
Radiological, biomechanical and histopathological characteristics of rat brain in Kaolin-induced hydrocephalus
}

\author{
M. Yavuz Samanci, MD ${ }^{1}$, Suat Erol Celik, Assoc. Prof. ${ }^{2}$, \\ Zafer Unsal Coskun, Prof. ${ }^{3}$, Deniz Ozcan, MD ${ }^{4}$
}

\author{
${ }^{1}$ Department of Neurosurgery, Istanbul Health Research and \\ Application Centre, Baskent University, Istanbul, TURKEY \\ 2 Department of Neurosurgery, Okmeydani Training and Research \\ Hospital, University of Health Sciences, Istanbul, TURKEY \\ 3 Department of Radiology, Okmeydani Training and Research \\ Hospital, University of Health Sciences, Istanbul, TURKEY \\ ${ }^{4}$ Department of Pathology, Okmeydani Training and Research \\ Hospital, University of Health Sciences, Istanbul, TURKEY
}

\begin{abstract}
Objective: A better understanding of the pathophysiology and underlying mechanisms of brain damage in hydrocephalus is vital in developing diagnostic, observational and treatment tools that will have an impact on hydrocephalus outcomes. In this study, we aimed to demonstrate the radiological, biomechanical and histopathological characteristics of rat brain tissue in an experimental hydrocephalus model.

Materials and Methods: Thirty-six male Sprague-Dawley rats (21 days old, weighing between 150 and 200 grams) were used in this study. Animals were randomly assigned to control $(n=6)$, 1-week hydrocephalus $(n=10)$, 2-week hydrocephalus ( $=10$ ) and 3-week hydrocephalus $(n=10)$ groups. Hydrocephalus was induced with cisternal kaolin injection and controls received sham injection. Magnetic resonance imaging was used to measure ventricle size and cortical thickness. Vital signs, cerebral blood flow (CBF), mechanical tests and brain histology were assessed.

Results: Three rats in the hydrocephalus group died during the follow-up, yielding an overall mortality of $10 \%$ among animals from hydrocephalus groups. Ventricular width, cross-sectional area of the lateral ventricles, ventricular index and ventricle / brain area ratio progressively increased and cortical thickness progressively decreased following kaolin injection. CBF was significantly lower at baseline than at 1st, 2nd and 3rd week ( $p<0.05$, for all). ICP was significantly elevated in all hydrocephalic groups in comparison with controls. EIT that was calculated from the first load-unload indentation test showed a significant increase at 2 nd week postinjection $(p=0.0001)$, indicating increased intracranial stiffness. However, this significant difference disappeared at 3rd week $(p=0.956)$. Quantitative immunohistochemistry showed that hydrocephalic brains demonstrated significantly less NeuN-positive cells and significantly higher IBA-1-positive microglia and glial fibrillary acidic protein positive astrocytes cells in the cortex.
\end{abstract}

Discussion and Conclusion: Cisternal kaolin injection causes varying degrees of
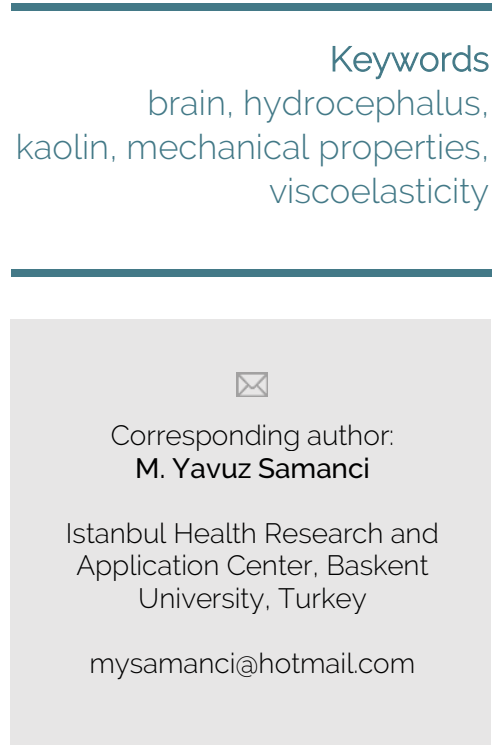

Copyright and usage. This is an Open Access article, distributed under the terms of the Creative Commons Attribution Non-Commercial No Derivatives License (https://creativecommons .org/licenses/by-nc-nd/4.0/) which permits noncommercial re-use, distribution, and reproduction in any medium, provided the original work is unaltered and is properly cited.

Thaltered and is property cited. Neurosurgery must be obtained for commercial re-use or in order to create a derivative work.

ISSN online 2344-4959

(C) Romanian Society of Neurosurgery

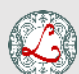

First published

October 2019 by

London Academic Publishing wwww.lapub. co.uk 
ventricular enlargement in a rat model and hydrocephalus might contribute to neuronal and axonal damage and alter brain stiffness through axonal stretching or local hypoperfusion progressively over a period of days to months. As shown in this study, irreversible changes in viscoelastic behaviour and cellular structure develop in the late stages of hydrocephalus, suggesting the importance of early intervention in the treatment of hydrocephalus.

\section{INTRODUCTION}

The basic definition of hydrocephalus is "an abnormal accumulation of cerebrospinal fluid (CSF) within the ventricles of the brain" [13]. The estimated prevalence is $1-1.5 \%$ and the incidence of congenital hydrocephalus is approximately $0.9-1.8 / 1000$ births $[17,23]$. Early onset hydrocephalus often results in the poorest neurological outcomes, with approximately $80 \%$ of patients suffering with residual neurological deficits [21].

Experimental animal models have been developed using various methods and agents to induce hydrocephalus or through genetic mutations in rodents. Although none of these models can fully mimic human condition, they can provide basic information that contributes to better understanding the pathogenesis of hydrocephalus and underlying causes. Although ventriculomegaly occurs naturally in congenital rat models, they are not ideal for long-term studies unless hydrocephalus is surgically intervened. Thus, the most common method of inducing experimental hydrocephalus without genetic mutation is the cisternal kaolin injection model that was introduced in the 1930s [19]. Kaolin is injected into the cisterna magna and spreads in the subarachnoid space, where it induces an inflammatory reaction and leads to an obstruction in the CSF pathways [8]. It is a simple, inexpensive and consistent way of inducing hydrocephalus in experimental animals [15].

Both clinical hydrocephalus and experimental hydrocephalus are often associated with symptoms of increased intracranial pressure (ICP) with ventricular dilatation. Understanding the biomechanical properties of the hydrocephalic brain can help in predicting mechanisms, simulating the disease and creating a treatment protocol. However, due to the complexity of the brain and the surrounding structures, data on the mechanical properties of living neural tissue is limited and variable $[10,22]$.

In this study, it was aimed to demonstrate the radiological, biomechanical and histopathological features of rat brain tissue in kaolin-induced hydrocephalus model.

\section{MATERIALS AND METHODS}

All animal experiments were conducted in accordance with the Institutional Animal Care and Use Committee of Istanbul University guide for the care and use of laboratory animals in consultation with institutional veterinarians. Specific protocols used in this study were approved by Istanbul University Laboratory Animals Local Ethics Committee (2013/47). Anaesthesia, preoperative animal preparation, anaesthesia delivery, perioperative analgesia practices, and surgical protocols were optimized to minimize trauma to the animals.

Thirty-six male pathogen-free Sprague-Dawley rats (age, 21 days; weight, 150-200 g) were maintained on a 12-hour light/dark cycle and had free access to water and pellet food. Animals were randomly assigned to control group $(n=6)$, one-week hydrocephalus group $(n=10)$, two-week hydrocephalus group $(n=10)$ and three-week hydrocephalus group $(n=10)$. All hydrocephalus groups underwent cisternal $0.02 \mathrm{~mL}$ sterile kaolin (200 mg / $\mathrm{mL}$ kaolin in $0.9 \%$ saline solution) injections, whereas controls received sham injection. All groups underwent magnetic resonance imaging (MRI), mechanical tests and histopathological examination.

\section{Induction of Experimental Hydrocephalus}

Rats were anesthetized with ketamine $\mathrm{HCl}$ (Ketalar, Parke Davis-Eczacıbaşı, Istanbul) and Xylazine (Rompun, Bayer, Istanbul) before surgical procedures. The head was secured in a stereotactic frame and a small vertical incision was made over the back of the neck from the top of the occiput to C1. The nuchal muscle layers were divided in the midline and retracted laterally to expose the atlantooccipital membrane (FIGURE 1). In all rats in the hydrocephalus groups, $0.02 \mathrm{ml}$ kaolin suspension was injected slowly into the cisterna magna through a 27-gauge needle. Control rats were subjected to sterile saline injection. The muscle layers and skin were sutured and rats were allowed to recover. After recovery from anaesthesia, rats were kept at room temperature and provided with standard chow and water ad libitum. They were examined daily for clinical signs of illness. Rats were weighed daily and monitored for neurological deficits. 


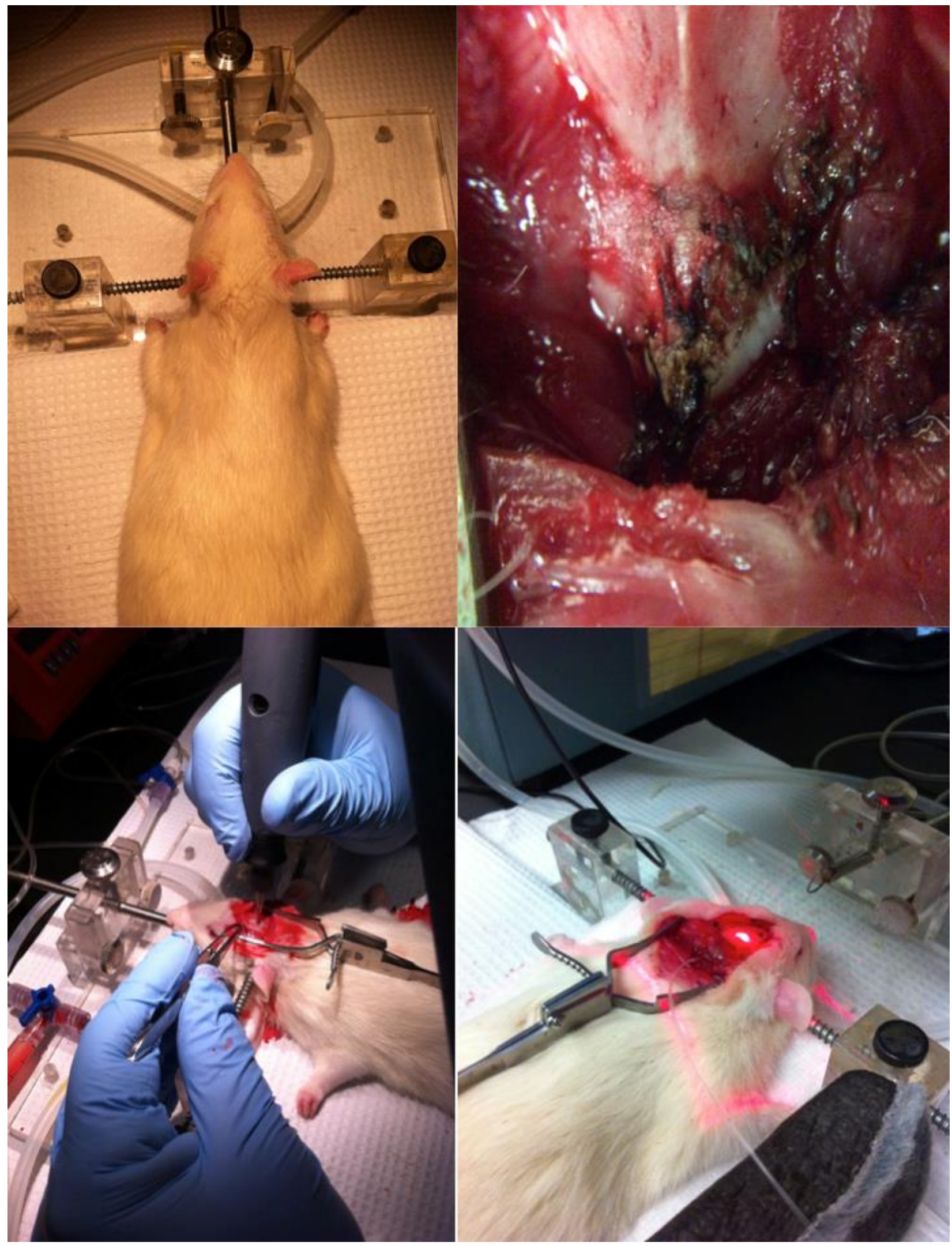

FIGURE 1. Basic demonstration of animal preparation. Custom custom-made stereotactic frame (upper left), atlanto-occipital membrane (upper right), preparation of cranial windows (lower left), and cerebral blood flow measurement with laser speckle microcirculation imager and pressure transmitter probe in the cisterna magna for monitoring intracranial pressure (lower right) can be seen. 


\section{Magnetic Resonance Imaging}

MRI studies were performed under general anaesthesia by the use of a human MR scanner equipped with a 48-cm bore magnet operating at a field of 1.5 T (Brivo MR355, GE Healthcare, Waukesha, US) with a custom coil to obtain T2weighted images of the brain in the coronal plane. The total area of the lateral ventricles and the brain area were evaluated by a radiologist using the PACS workstation (Neorad ${ }^{\circledR}$, Teleradiology \& 3D, Serman Medical Information, Istanbul, Turkey) on the coronal brain section that includes the anterior wall of the third ventricle. The frontal ventricle-to-brain area ratio, ventricle width index and cortical thickness measurements were performed as described by Shulyakov et al. [26].

\section{Animal Preparation}

After MRI, spontaneously breathing rats were induced with $4 \%$ isoflurane gas delivered by $100 \%$ oxygen. The rats were placed in the supine position on a homoeothermic blanket system and instrumented with a rectal temperature probe and foot pulse oximeter to continuously monitor body temperature, blood oxygen saturation, and heart rate. Under the operating microscope, the trachea was intubated with a $16 \mathrm{G}$ tube through a tracheostomy. The rats were then maintained with mechanical ventilation at fixed tidal volume $(7 \mathrm{~mL} / \mathrm{kg})$ and inspired oxygen (40\%). The left common carotid artery was dissected and cannulated for continuous blood pressure monitoring, serial blood gas analysis and fluid replacement. Isoflurane was titrated to maintain a mean arterial pressure of $80-120 \mathrm{~mm} \mathrm{Hg}$ and oxygen saturation $>90 \%$. The rats were then positioned prone, fixed in a custom-made stereotactic frame and previous midline incision was used to expose the skull. The periosteum was incised and dissected. The skull was bilaterally thinned using a high-speed drill equipped with a 1.8-mm diamond burr bit to create bilateral penetrating cranial windows, leaving the dura-arachnoid membranes intact. A pressure transmitter probe was inserted into the cisterna magna for monitoring ICP. For cerebral blood flow (CBF) measurement, Laser Speckle Microcirculation Imager was positioned over the rat with the desired cranial window aligned in the camera field of view. Speckle images within a $1.2-\mathrm{cm}$ $\times 1.6-\mathrm{cm}$ region were acquired at a frequency of 50 $\mathrm{Hz}$ with a resolution of $100 \mathrm{~mm} /$ pixel, with $18.526 \mathrm{~K}$ points/perfusion unit value. Baseline images were recorded and CBF in arbitrary perfusion units was obtained throughout the procedure. Physiological data were recorded continuously during the procedure. Baseline and hourly blood gas levels were analysed in all animals. The core temperature was measured via rectal probes and used as a reference for brain temperature.

\section{Mechanical tests}

A custom-made indentation instrument with a halfspherical indenter was used. The indenter was fastened to the custom-made stereotactic frame and it was positioned over the centre of craniectomy to achieve a planar initial contact. With the use of previously described mechanical force parameters $[27,31]$, a standard sequence of indentation tests including loading-unloading test, load and hold test, and multicycle loading-unloading test was performed. Indentation modulus (EIT), viscous deformation and viscous nature of the material were assessed. Recovery periods of approximately 15 minutes were allowed between tests.

\section{Histological Examination}

Animals were overdosed with pentobarbital after mechanical testing, and transcardially perfused with saline and then $4 \%$ paraformaldehyde. Brains were post-fixed and subsequently immersed in the same fixative solution overnight at $4{ }^{\circ} \mathrm{C}$ and then washed in phosphate-buffered saline and stored in ethanol until processing. Coronal slices were sectioned and embedded in paraffin. The paraffinized tissue slices were sectioned at $5 \mathrm{~mm}$ thickness. To assess neuronal integrity, activated microglia, and activated astrocytes, the following primary antibodies were used: anti-FOX3 (NeuN) 1:2000, anti-lba-1 1:1000, and anti-glial fibrillary acidic protein (GFAP) 1:500. Images from the cortex were taken at 200x magnification. Using Image J, NeuN, Iba-1, and GFAP stained cells were counted.

\section{Statistical analysis}

Statistical analysis was performed using SPSS 18 (IBM Corp., Armonk, NY, USA). All data are expressed as mean \pm standard error of the mean. Comparison across the groups was made by using analysis of variance. Statistical significance was accepted at $p<$ 0.05 . 


\section{RESULTS}

In total, thirty rats underwent induction of hydrocephalus. None of the rats in the hydrocephalus groups experienced major neurological deficits. Three rats in the 3-week hydrocephalus group died during the study, yielding an overall mortality of $10 \%$ among animals from hydrocephalus groups. Two rats died during the $3 \mathrm{rd}$ week of hydrocephalus and no cause could be identified. One rat died during indentation testing, probably due to anesthesia overdose. Therefore, the assessments were performed with a total of 33 rats.

During the study, all animals, regardless of group, showed an increase in body weight $(p<0.0001)$.
Hydrocephalic rats lost weight after kaolin injection, typically for 2-3 days. By 1-week post-injection, the rats started gaining weight. Nonetheless, rats in the hydrocephalus groups weighed less than controls regardless of hydrocephalus week $(p=0.0014$ for one-week hydrocephalus; $p<0.0001$ for two-week hydrocephalus and $p<0.0001$ for three-week hydrocephalus).

MRI imaging showed that the ventricular width, cross-sectional area of the lateral ventricles, ventricular index and ventricle / brain area ratio progressively increased and cortical thickness progressively decreased following kaolin injection (TABLE 1) (FIGURE 2)

\begin{tabular}{|c|c|c|c|c|c|c|}
\hline & $\begin{array}{c}\text { MRI } \\
\text { parameters }\end{array}$ & $\begin{array}{l}\text { Ventricular } \\
\text { width }\end{array}$ & $\begin{array}{c}\text { Cross-sectional } \\
\text { area } \\
\text { of the lateral } \\
\text { ventricles }\end{array}$ & $\begin{array}{l}\text { Ventricular } \\
\text { index }\end{array}$ & $\begin{array}{c}\text { Ventricle / } \\
\text { brain area } \\
\text { ratio }\end{array}$ & $\begin{array}{l}\text { Cortical } \\
\text { thickness }\end{array}$ \\
\hline \multirow[t]{2}{*}{$\begin{array}{l}\text { Hydrocephalic } \\
\text { rats }\end{array}$} & $\begin{array}{l}1^{\text {st }} \text { week vs. } \\
2^{\text {nd }} \text { week }\end{array}$ & $<0.0001$ & $<0.0001$ & $<0.0001$ & 0.0005 & 0.0142 \\
\hline & $\begin{array}{l}1^{\text {st }} \text { week vs. } \\
3^{\text {rd }} \text { week }\end{array}$ & $<0.0001$ & $<0.0001$ & $<0.0001$ & $<0.0001$ & $<0.0001$ \\
\hline \multirow[t]{2}{*}{ Control rats } & $\begin{array}{l}1^{\text {st }} \text { week vs. } \\
2^{\text {nd }} \text { week }\end{array}$ & 0.99 & 0.99 & 0.96 & 0.86 & 0.87 \\
\hline & $\begin{array}{l}1^{\text {st }} \text { week vs. } \\
3^{\text {rd }} \text { week }\end{array}$ & 0.79 & 0.72 & 0.68 & 0.61 & 0.50 \\
\hline
\end{tabular}

TABLE 1. Statistical evaluation of MRI parameters in hydrocephalic and control rats.

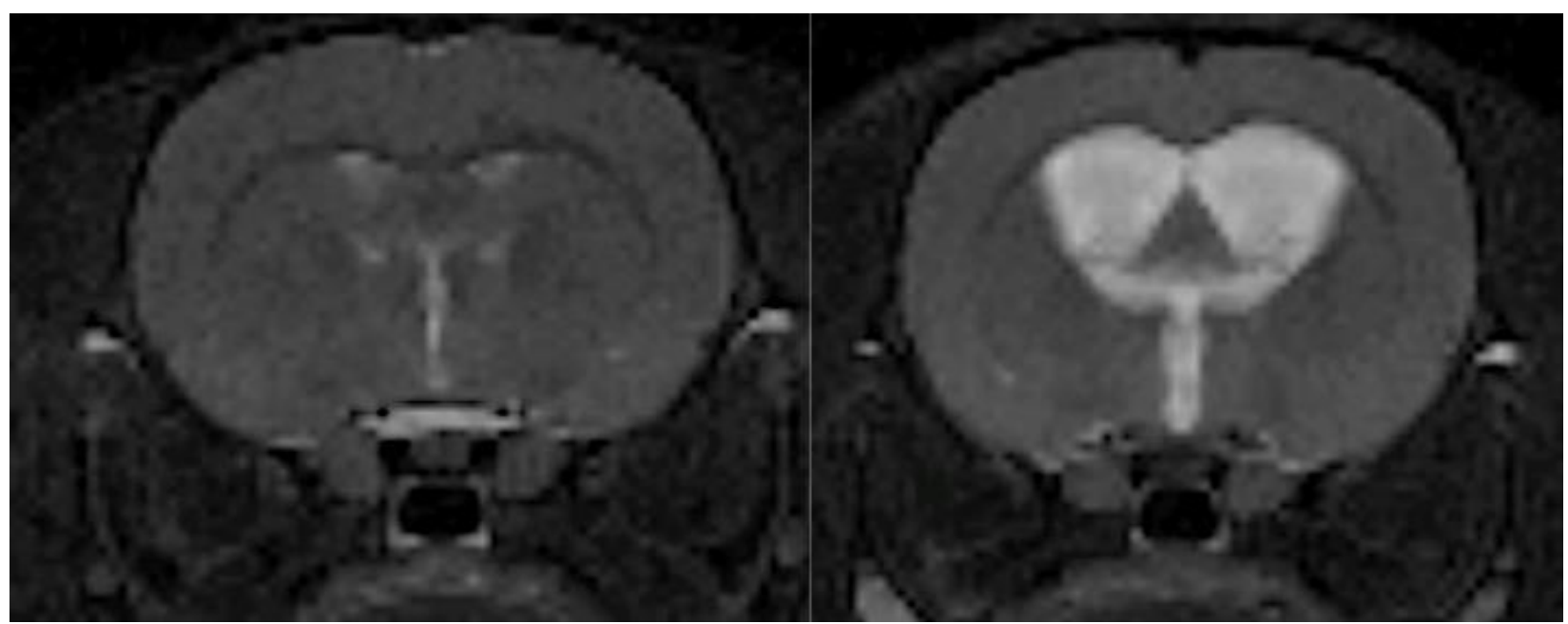

FIGURE 2. Magnetic resonance image demonstrating increase in ventricular size in a hydrocephalic rat at 3rd week (right) compared to a control rat (left).

In control rats, $\mathrm{CBF}$ was significantly lower at baseline than at 1 st, 2nd and 3rd week ( $<<0.05$, for all). Hydrocephalic rats also showed an increase in CBF with time, but this was not significant $(p=0.2429)$. Hydrocephalic rats at 1 st week had a lower CBF than controls; however, the difference was not significant 
$(p=0.3134)$. At 2nd and 3rd weeks, hydrocephalic rats had a significantly lower CBF than controls with a highest percentage reduction of $59 \%(p<0.0001)$ (TABLE 2).

\begin{tabular}{|c|c|c|c|c|c|c|c|}
\hline & $\begin{array}{l}\text { Mechanical } \\
\text { parameters }\end{array}$ & CBF & ICP & $\begin{array}{l}\text { Heart } \\
\text { rate }\end{array}$ & $\mathrm{E}_{\mathrm{IT}}$ & $\begin{array}{l}\text { Strain during } \\
\text { load-hold }\end{array}$ & $\begin{array}{l}\text { Strain during } \\
\text { multi-cycle }\end{array}$ \\
\hline \multirow[t]{2}{*}{$\begin{array}{l}\text { Hydrocephalic } \\
\text { rats }\end{array}$} & $\begin{array}{l}1^{\text {st }} \text { week vs. } \\
2^{\text {nd }} \text { week }\end{array}$ & 0.48 & $<0.0001$ & $<0.0001$ & $<0.0001$ & $<0.0001$ & 0.0214 \\
\hline & $\begin{array}{l}1^{\text {st }} \text { week vs. } \\
3^{\text {rd }} \text { week }\end{array}$ & 0.1865 & 0.4255 & 0.0145 & 0.9443 & $<0.0001$ & 0.1340 \\
\hline \multirow{3}{*}{$\begin{array}{l}\text { Control rats } \\
\text { vs. } \\
\text { Hydrocephalic } \\
\text { rats }\end{array}$} & $\begin{array}{ll}\text { Control vs. } \\
1^{\text {st }} \text { week }\end{array}$ & 0.0004 & $<0.0001$ & $<0.0001$ & 0.8842 & 0.0002 & 0.0555 \\
\hline & $\begin{array}{l}\text { Control vs. } \\
2^{\text {nd }} \text { week }\end{array}$ & $<0.0001$ & $<0.0001$ & $<0.0001$ & $<0.0001$ & 0.0001 & 0.0176 \\
\hline & $\begin{array}{l}\text { Control vs. } \\
3^{\text {rd }} \text { week }\end{array}$ & $<0.0001$ & $<0.0001$ & $<0.0001$ & 0.956 & $<0.0001$ & 0.0082 \\
\hline
\end{tabular}

TABLE 2. Statistical evaluation of physiological and mechanical parameters in hydrocephalic and control rats CBF: cerebral blood flow; ICP: intracranial pressure; EIT: indentation modulus

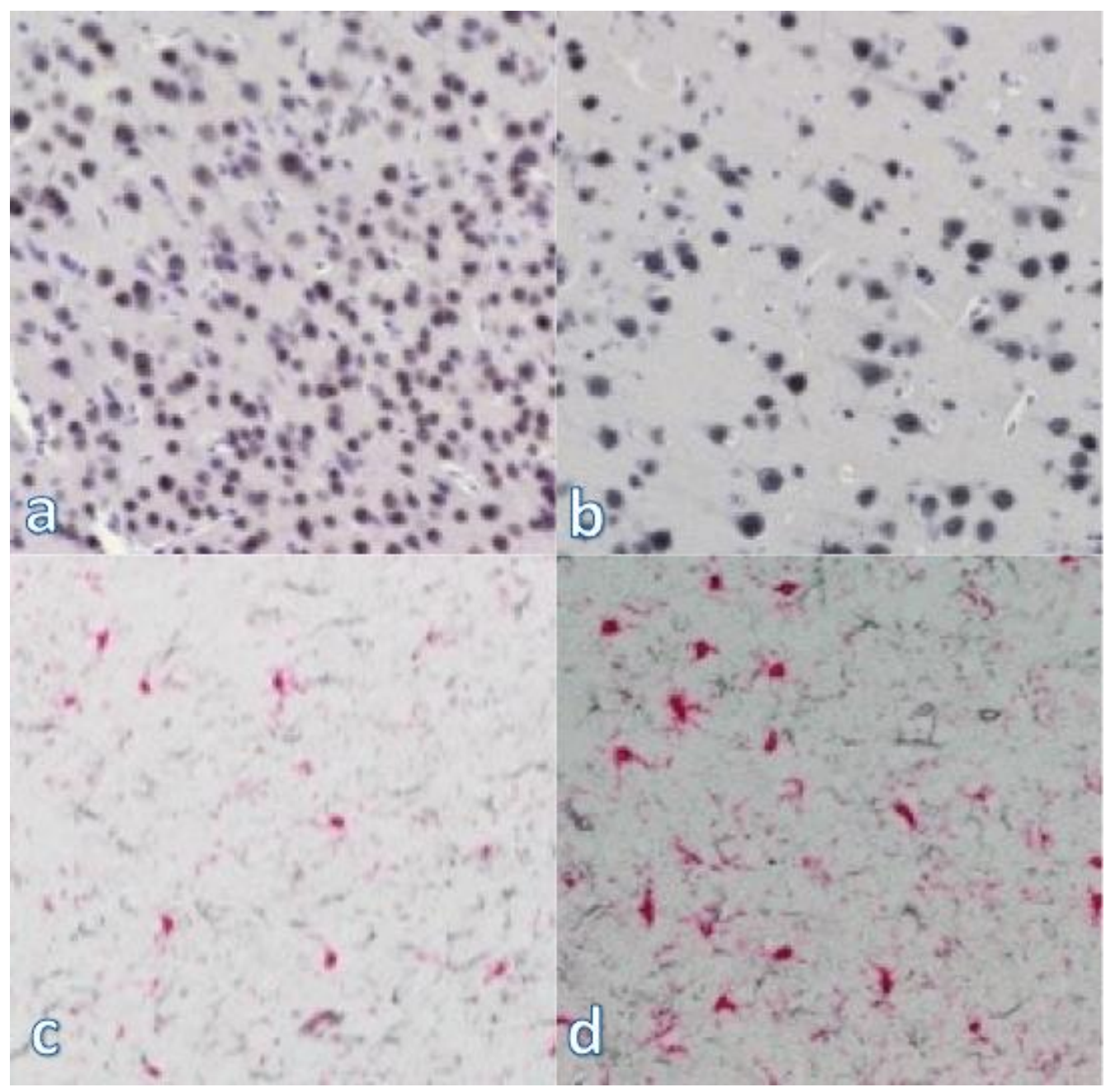

FIGURE 3. Representative histomicrographs showing significantly decreased NeuN-positive cells in the cortex of rats in the hydrocephalus group at 3rd week (b) compared to controls (a), and significantly increased Iba-1-positive microglia (red) and GFAPpositive astrocyte cells (gray) in the cortex of rats in the hydrocephalus group at 3rd week (d) compared to controls (c). 
For the control and hydrocephalic groups, the indentation tests were associated with an ICP increase up to $20 \%$. EIT that was calculated from the first load-unload indentation test showed a significant increase at 2 nd week post-injection (148 $\mathrm{kPa}$ vs. $278 \mathrm{kPa}, \mathrm{p}=0.0001$ ), indicating increased intracranial stiffness. However, this significant difference disappeared at 3rd week $(p=0.956)$. In the load-hold indentation test, control and hydrocephalic brains exhibited gradual deformation and the associated intracranial strain was significantly greater at each time points in the hydrocephalus groups $(p=0.0002$ at 1st week, $p=0.0001$ at 2 nd week and $p<0.0001$ at 3rd week). The multi-cycle indentation test also caused gradual deformation of the intracranial contents in all groups, but there was no significant difference between groups $(p=0.0555$ at 1 st week, $p=0.082$ at 2nd week and $p=0.176$ at 3rd week) (TABLE 2).

Systemic blood pressure and mean arterial pressure were stable during mechanical tests; however, due to increased ICP, cerebral perfusion pressure and CBF decreased. After withdrawal of the indenter, blood flow returned immediately to baseline values I all groups. Baseline core temperatures were not statistically different between all groups and changes were not significant during indentation (TABLE 2).

ICP in controls was $6.5 \pm 0.86 \mathrm{mmHg}$. Compared to controls, ICP was significantly elevated in all hydrocephalic groups, with the pressure being highest at 2 nd week ( $p<0.0001$ at all-time points). ICP showed a rapid pressure rise during indentation and returned immediately to baseline values after withdrawal in all groups. During indentation, bradycardia was identified at the point of maximal ICP (TABLE 2).

Quantitative analyses of NeuN-positive, IBA-1positive, and GFAP-positive cells in the cortex of animals with hydrocephalus demonstrated significantly less NeuN-positive cells that reflects altered neuronal integrity, and significantly more Iba1-positive microglia and GFAP-positive astrocyte cells that indicate higher inflammatory signals (FIGURE 3).

\section{DISCUSSION}

To investigate the radiological, biomechanical and histopathological changes in experimental hydrocephalus, we analyzed the impact of kaolininduced hydrocephalus in rats. The present data indicate that kaolin-induced hydrocephalus created a reproducible hydrocephalus model with altered brain morphology along with disturbed mechanical properties and neuronal integrity.

Besides genetic mutations, experimental animal models have been developed using numerous agents to induce hydrocephalus $[8,15]$. All of these models provide important information to understand the causes and potential treatments of hydrocephalus. The most commonly used method is the injection of kaolin into the cisterna magna [9] and it is an inexpensive, simple and reliable method that has been previously studied in rats $[6,7,11,12,18]$. In our study, the experimental rats were particularly 21 day old rats, as it corresponds to the first 6-month period of human brain development in which cerebral myelination is rapid $[24,30]$. The rats in our study tolerated the kaolin injection fairly well with acceptable levels of mortality $(10 \%$ died during 3 weeks, one possibly due to anesthesia overdose) and no evidence of hemorrhage was observed following removal of the brain. Compared to higher rates of mortality in the literature, it was thought that the difference might be due to post-operative animal care, animal breed used and the chemical properties of kaolin $[5,20]$. However, it should be noted that none of these models, including kaolin-induction method, is perfect in imitating human conditions.

Although kaolin-induced hydrocephalus model offers dose-dependent responses to some extent, there is variable dispersion of kaolin in the subarachnoid space, and this may account for the relatively unpredictable rate and magnitude of ventricular dilatation [8]. Consistent with the literature, in our study, kaolin presumably caused a moderate to severe hydrocephalus with a ventricle/brain area ratio of $0.105 \pm 0.02$ at 3 weeks, compared to $0.018 \pm 0.002$ at baseline. Kaolin causes an inflammatory response, thus causing blockage of the fourth ventricle and mimicking hydrocephalus caused by meningitis. Although this model has been criticized for its inflammatory effects such as evident macrophages, CD4- and CD8- lymphocytes in the subarachnoid space and in surrounding brain parenchyma, and reactive microglia in the white matter surrounding the ventricles $[7,16,25]$, it was reported that kaolin had clearly been ingested by macrophages and there were minimal neutrophils and eosinophils at 10th day post-injection with histologically unaltered brainstem and cerebellum 
adjacent to kaolin collections [29]. Brain injury in hydrocephalus is a multifactorial process marked by ventricular enlargement leading to stretching of axons with concomitant cortical compression. However, these histologically evident progressive destructive changes can be difficult to quantify due to profound tissue distortions [16]. In our study, quantitative analyses of NeuN-positive, IBA-1positive, and GFAP-positive cells in the cortex of animals with hydrocephalus demonstrated significantly less NeuN-positive cells and significantly more Iba-1-positive microglia and GFAP-positive astrocyte cells.

Due to the complexity of the brain and the surrounding meningeal structure, information about the mechanical properties of living neural tissue is insufficient $[10,22]$. To learn about the mechanical changes and to better understand the physical mechanisms involved in hydrocephalus, it is necessary to learn about the mechanical properties of the brain in vivo [1]. The main advantage of in vivo testing is that the tissue structure remains largely intact, as close to its natural state as possible [4]. It is widely known that the mechanical properties of neural tissues are associated with their microstructure [2]. Thus, changes in tissue microstructure can be reflected as an altered stiffness. In our study, the live brain mechanical properties reflected a combination of several different anatomical and physiological systems including the dura mater, the intact CSF system, and the brain itself. The stiffness of cortical gray matter increased despite the differences in tissue microstructure at 2 nd week, similar to the study by Shulyakov et al. [26]. However, Juge et al. [14] did not find such an increase in the same hydrocephalus rat model. The main difference of their study was that they used MR elastography to measure brain stiffness and the contribution of hydrostatic pressure to mechanical properties was eliminated by elastography analysis method [28]. Despite the increase at 2nd week, the difference between controls and hydrocephalic group disappeared at 3rd week. Regarding this, it can be suggested that microstructural rearrangement occurs in brain during chronic phase of hydrocephalus possibly through neuronal damage. This damage was also demonstrated in our study by significantly less NeuN-positive cells in the hydrocephalic group at 3rd week. The absence of permanent change in viscoelastic behaviour in the brain in the early stages of hydrocephalus in our study shows the importance of early intervention in the treatment of hydrocephalus.

The main limitation of our study was that we could not use an animal MRI equipped with a higher magnetic field strength. However, in a previous study, 1.0T MRI was shown to be a reliable equipment to assess MRI features in experimental hydrocephalus [3].

\section{CONCLUSION}

Cisternal kaolin injection causes varying degrees of ventricular enlargement in a rat model and reflects the hydrocephalus pathology seen in foetuses and premature infants in some aspects. Hydrocephalus might contribute to neuronal and axonal damage and alter brain stiffness through axonal stretching or local hypoperfusion progressively over a period of days to months. The absence of permanent change in viscoelastic behaviour in the brain in the early stages of hydrocephalus necessitates early intervention.

\section{REFERENCES}

1. Azzi GM, Canady Al, Ham S, Mitchell JA (1999) Kaolininduced hydrocephalus in the hamster: temporal sequence of changes in intracranial pressure, ventriculomegaly and whole-brain specific gravity. Acta neuropathologica 98 (3):245-250. doi:10.1007/s00401005 1076

2. Bilston LE (2011) Neural Tissue Biomechanics. Studies in Mechanobiology, Tissue Engineering and Biomaterials, vol 3. Springer-Verlag Berlin Heidelberg. doi:10.1007/978-3642-13890-4

3. Castro SC, Machado HR, Catalao $\mathrm{CH}$, Siqueira BA, Simoes AL, Lachat JJ, Lopes Lda S (2012) 0.1T magnetic resonance image in the study of experimental hydrocephalus in rats. Accuracy of the method in the measurements of the ventricular size. Acta cirurgica brasileira 27 (11):768-772

4. Cheng S, Clarke EC, Bilston LE (2008) Rheological properties of the tissues of the central nervous system: a review. Medical engineering \& physics 30 (10):1318-1337. doi:10.1016/j.medengphy.2008.06.003

5. Davis GB, Kohandel M, Sivaloganathan S, Tenti G (2006) The constitutive properties of the brain paraenchyma Part 2. Fractional derivative approach. Medical engineering \& physics 28 (5):455-459. doi:10.1016/j.medengphy.2005.07. 023

6. Del Bigio MR, Crook CR, Buist R (1997) Magnetic resonance imaging and behavioral analysis of immature rats with 
kaolin-induced hydrocephalus: pre- and postshunting observations. Experimental neurology 148 (1):256-264. doi:10.1006/exnr.1997.6644

7. Del Bigio MR, Zhang YW (1998) Cell death, axonal damage, and cell birth in the immature rat brain following induction of hydrocephalus. Experimental neurology 154(1):157-169. doi:10.1006/exnr.1998.6922

8. Di Curzio DL (2018) Animal Models of Hydrocephalus. Open Journal of Modern Neurosurgery 8:57-71. doi:https:// doi.org/10.4236/ojmn.2018.81004

9. Dixon WE HH (1932) Experimentelle Hypertonie durch Erohung des intrakaniellen Druckes. Arch Exp Pathol Pharmakol 166:265-275

10. Goldsmith W (2001) The state of head injury biomechanics: past, present, and future: part 1 . Critical reviews in biomedical engineering 29 (5-6):441-600

11. Hochwald GM, Boal RD, Marlin AE, Kumar AJ (1975) Changes in regional blood-flow and water content of brain and spinal cord in acute and chronic experimental hydrocephalus. Developmental medicine and child neurology Supplement (35):42-50

12. Hochwald GM, Nakamura S, Camins MB (1981) The rat in experimental obstructive hydrocephalus. Zeitschrift fur Kinderchirurgie: organ der Deutschen, der Schweizerischen und der Osterreichischen Gesellschaft fur Kinderchirurgie $=$ Surgery in infancy and childhood 34 (4):403-410. doi:10.1055/s-2008-1063383

13. Johnston I, Teo C (2000) Disorders of CSF hydrodynamics. Child's nervous system: ChNS: official journal of the International Society for Pediatric Neurosurgery 16 (1011):776-799. doi:10.1007/s003810000383

14. Juge $L$, Pong AC, Bongers A, Sinkus R, Bilston LE, Cheng $S$ (2016) Changes in Rat Brain Tissue Microstructure and Stiffness during the Development of Experimental Obstructive Hydrocephalus. PloS one 11 (2):e0148652. doi:10.1371/journal.pone.0148652

15. Khan OH, Del Bigio MR (2006) Experimental models of hydrocephalus. In: Tatlisumak TaF, M., (ed) Handbook of Experimental Neurology: Methods and Techniques in Animal Research. Cambridge University Press, pp 457-471. doi:https://doi.org/10.1017/CBO9780511541742.026

16. Khan OH, Enno TL, Del Bigio MR (2006) Brain damage in neonatal rats following kaolin induction of hydrocephalus. Experimental neurology 200 (2):311-320. doi:10.1016/j. expneurol.2006.02.113

17. Lemire RJ (1988) Neural tube defects. Jama 259 (4):558-562

18. Li J, McAllister JP, 2nd, Shen Y, Wagshul ME, Miller JM, Egnor MR, Johnston MG, Haacke EM, Walker ML (2008) Communicating hydrocephalus in adult rats with kaolin obstruction of the basal cisterns or the cortical subarachnoid space. Experimental neurology 211 (2):351361. doi:10.1016/j.expneurol.2007.12.030
19. Lindauer MA, Griffith, J.Q. (1938) Cerebrospinal Pressure, Hydrocephalus and Blood Pressure in Cat Following Intracisternal Injection of Colloidal Kaolin. Proceedings of the Society for Experimental Biology and Medicine 39:547549.

20. McHedlishvili G, Nikolaishvili L, Itkis M (1979) Pathophysiological mechanisms of brain edema development: role of tissue factors. Stroke 10 (1):52-57. doi:10.1161/01.str.10.1.52

21. Moritake K, Nagai H, Miyazaki T, Nagasako N, Yamasaki M, Sakamoto H, Miyajima M, Tamakoshi A (2007) Analysis of a nationwide survey on treatment and outcomes of congenital hydrocephalus in Japan. Neurologia medicochirurgica 47 (10):453-460; discussion 460-451. doi:10.2176/nmc.47.453

22. Ommaya AK (1968) Mechanical properties of tissues of the nervous system. Journal of biomechanics 1 (2):127-138. doi:10.1016/0021-9290(68)90015-8

23. Persson EK, Hagberg G, Uvebrant P (2005) Hydrocephalus prevalence and outcome in a population-based cohort of children born in 1989-1998. Acta paediatrica 94 (6):726732. doi:10.1111/j.1651-2227.2005.tb01972.x

24. Segawa W (1961) Rheological Equations of Generalized Maxwell Model and Voigt Model in Three-Dimensional, Non-Linear Deformation. Journal of the Physical Society of Japan 16:320-323. doi:10.1143/JPSJ.16.320

25. Shinoda M, Olson L (1997) Immunological aspects of kaolininduced hydrocephalus. The International journal of neuroscience 92 (1-2):9-28. doi:10.3109/00207459708 986386

26. Shulyakov AV, Buist RJ, Del Bigio MR (2012) Intracranial biomechanics of acute experimental hydrocephalus in live rats. Neurosurgery 71 (5):1032-1040. doi:10.1227/NEU. Ob013e3182690a0c

27. Shulyakov AV, Fernando F, Cenkowski SS, Del Bigio MR (2009) Simultaneous determination of mechanical properties and physiologic parameters in living rat brain. Biomechanics and modeling in mechanobiology 8 (5):415425. doi:10.1007/s10237-008-0147-9

28. Sinkus R, Tanter M, Xydeas T, Catheline S, Bercoff J, Fink M (2005) Viscoelastic shear properties of in vivo breast lesions measured by MR elastography. Magnetic resonance imaging 23 (2):159-165. doi:10.1016/j.mri.2004.11.060

29. Slobodian I, Krassioukov-Enns D, Del Bigio MR (2007) Protein and synthetic polymer injection for induction of obstructive hydrocephalus in rats. Cerebrospinal fluid research 4:9. doi:10.1186/1743-8454-4-9

30. Yamamoto Y, Moritake K, Nagai H, Sato M (2004) Quantitative estimation of brain stiffness measured using a tactile biosensor in animal models. Neurological research 26 (6):622-627. doi:10.1179/016164104225016326

31. Zhang M, Zheng YP, Mak AF (1997) Estimating the effective Young's modulus of soft tissues from indentation tests-- 
nonlinear finite element analysis of effects of friction and large deformation. Medical engineering \& physics 19 (6):512-517. 